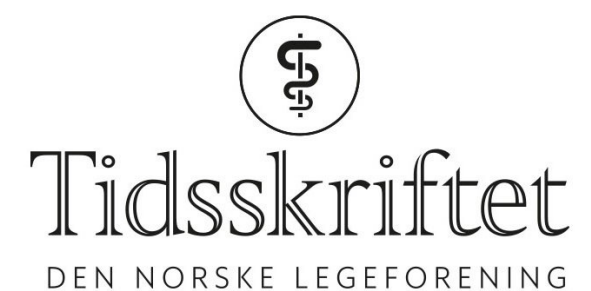

\title{
En levende bauta
}

INTERVJU

TORI FLAATTEN HALVORSEN

E-post:Tori.F.Halvorsen@gmail.com

Det var ingen selvfølge at det skulle gå bra med en 13-åring og den to år yngre broren med Downs syndrom da de ble satt på flyet fra Addis Abeba til Gardermoen.

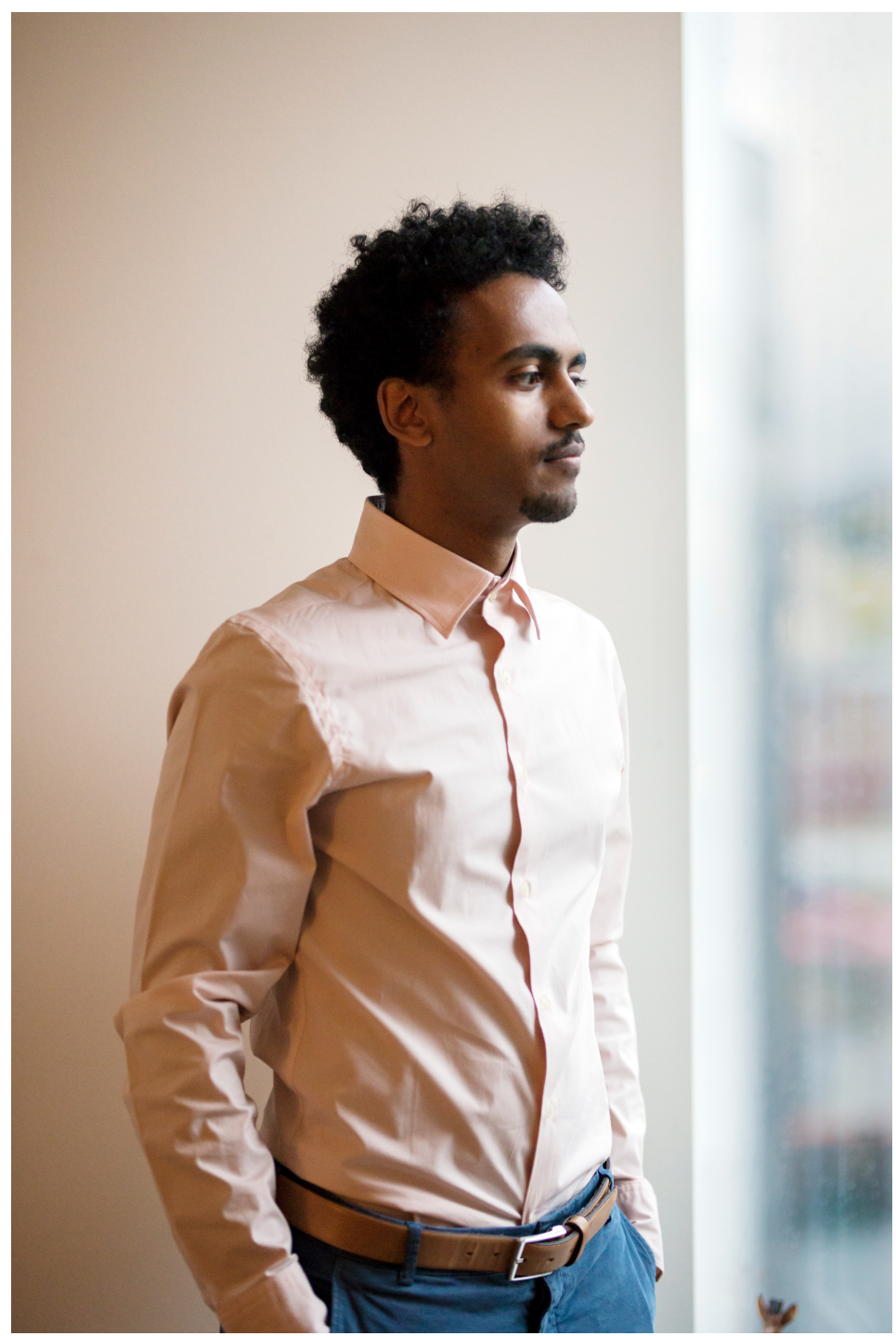

Foto: Kristine Lindebø

Et søvnig teppe ligger tungt over Oslo en søndag morgen høsten 2017. Det er bare på 
legevakten det er liv. Her rauser det inn mennesker til fots, per bil, i drosjer eller med ambulanser med og uten blålys eller sirener. Midt i kaoset av mer eller mindre syke mennesker fra hele verden holder Abdul Nuru øye med dem alle sammen. Den hvitkledde, den gang 23 år gamle legestudenten, med et brunt ansikt, store smilende mørke øyne, kraftige øyebryn og krøllete svart hår er på godfot med sykepleierne som administrerer inntaket av storbyens innbyggere. Abdul holder spesielt øye med de sykeste og de mest rusede i det neonopplyste venterommet. Likevel tar han seg tid til å tøyse med de sutrete ungene, informerer tynnhudete småbarnsforeldre og trøster dem som følger sine aldrende foreldre til legen. Mange er der for å tolke for sine. Abduls tålmodighet og ro ser ut til å smitte over på dem alle, også de som roper høyest.

\title{
Oppveksten
}

Kontrasten fra stemningen på legevakten for tre år siden og stemningen i leiligheten til ekteparet Nuru er slående. Innredningen er minimalistisk og trendy, i grått og hvitt. Ikke en pute eller et teppe minner om noe som er kjøpt utenfor Norges grenser. Abdul heller vin i glasset. Sara sender rundt et fat med franske oster. Ingen forstyrrer.

\author{
Abdul Nuru \\ Født 10. juli 1994 \\ Tolk for Tolketjenesten AS 2012-15 \\ Cand.med., Universitetet i Oslo 2013-19 \\ Medisinstudent i sykepleietjenesten 2013-17 \\ Førsteforfatter for en artikkel i Scandinavian Cardiovascular Journal 2018 \\ LIS1-lege, Diakonhjemmet sykehus og Oslo kommune 2019- \\ Legevaktlege, Os legevakt 2019-20 \\ Turnuslege/LIS1-lege, Kommunal akutt døgnenhet 2019- \\ Fastlege, Majorstukrysset legegruppe 2020-
}

På benken står det et lite fotografi i en enkel ramme. To gutter og en voksen kvinne står oppstilt foran noen busker et sted der ute i verden. Bildet gir en innfallsport til første spørsmål.

- Hvor er du oppvokst?

- Etiopia. I en liten landsby kalt Gimbi, 12 timers kjøretur på humpete og støvete veier fra hovedstaden Addis Abeba.

Den ene gutten på bildet har opplagt Downs syndrom. Den andre må være Abdul. Moren står i midten og holder forsiktig rundt sønnene sine. Hun ser rett i kamera med et noe alvorstungt blikk.

- Moren min var en varm, hardtarbeidende og smart kvinne. Hun ville at vi skulle få lære mest mulig, ikke minst ville hun legge til rette for lillebror, som jo hadde vansker for å lære. Hun fikk han inn i en barnehage som var drevet av det jeg tror var italienske nonner, forteller Abdul. Han har ikke lenger noen som kan svare på spørsmål fra barndommen.

Abdul peker på broren på bildet.

- Ingen visste hvorfor det gikk så tregt for Mabruk. Downs syndrom var nok helt ukjent for både lærere, moren og alle andre i landsbyen.

Lærerne brydde seg ikke om lille Mabruk, men Abdul hadde alltid oversikt over hvor broren var. Moren var ofte opptatt med butikken hun drev. Butikken lå vegg i vegg med rommet der guttene og moren bodde. Både butikken og hjemmet hadde inngang rett fra gaten. Sammen holdt de øye med sauene som sov bortenfor butikken. Innimellom dro moren den lange veien til Addis Abeba for å fylle opp butikkhyllene. Da var naboene ekstra 
oppmerksomme på guttene.

Hjemme ville mor at barna skulle snakke det offisielle språket, amharisk. Undervisningen på skolen foregikk på det lokale språket oromisk. På koranskolen som Abdul gikk på om kveldene, var det arabisk som gjaldt. Første året satt elevene på planker som balanserte på to steiner. Seinere ble det krakker. Gjorde elevene noe galt, ble de straffet av lærerne. Det skjedde gjerne i korridorene med åpne dører til klasserommene slik at alle kunne høre hva som skjedde.

Det som hele tiden har vært avgjørende, er å se kun én vei - og det er framover!

- Fortsatt skjønner jeg ikke hvorfor jeg ble pisket. Den ene gangen hadde jeg bare delt et viskelær. Vennen trengte å endre det han hadde skrevet, og da var det vel riktig å gi han viskelæret? undrer Abdul fortsatt, 15 år etter.

- Det høres ut som du forteller fra en film?

- Det er ikke sånn. Du må huske på én ting ... Abdul får en mer bestemt mine i ansiktet og fortsetter:

- Det som hele tiden har vært avgjørende, er å se kun én vei - og det er framover!

\section{Mor blir alvorlig syk}

Da Abdul akkurat var blitt tenåring, reiste moren til Norge for å besøke storesøsteren hans. Hun kom til Norge som kvoteflyktning etter at hun måtte rømme fra Addis Abeba til Kenya. Abdul har bare noen få minner om søsteren før hun flyttet fra landsbyen til hovedstaden. Hun hadde gitt han et kritt lenge før Abdul selv begynte på skolen. Så hadde de sett noen filmer sammen.

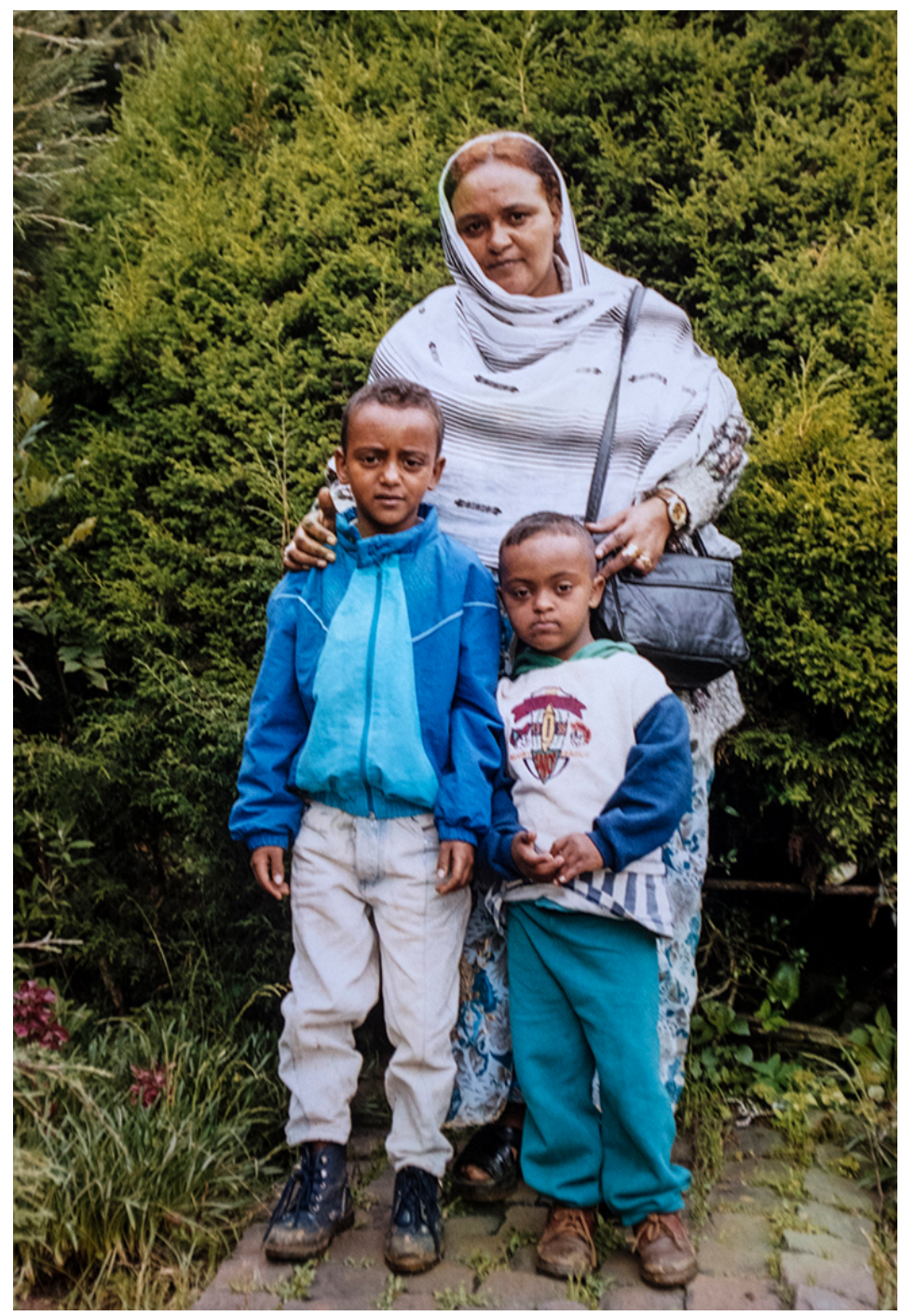


- Vi var av de få som hadde TV.

Under det korte oppholdet i Norge fikk moren stadfestet kreft i preterminal fase. Abdul husker at han hadde vært med moren til lege i landsbyen, men uten at det ble satt riktig diagnose. Moren måtte finne en utvei for sine to sønner som snart skulle bli foreldreløse. Løsningen ble to enveisflybilletter til Gardermoen, der søsteren sto klar for å ta imot sine to småbrødre, som hun ikke hadde sett på mange år.

- Men faren din?

- Han husker jeg ikke. Etter at de giftet seg, bodde han og mor sammen i Addis. Men han var ikke grei. Mor stakk med oss tre barna til landsbygda da jeg var liten. Vi så han aldri igjen. Jeg har ikke en gang sett et bilde av han.

- Jo, det har du, skyter Sara inn:- Det lille brudebildet som søsteren din har.

- Det er sant. Det er rart at jeg nesten har glemt det. Men det er bare så vidt man kan se ansiktet hans. Man ser han bare fra siden.

\section{Reisen til Norge}

- Det jeg husker best av alt fra reisen til Norge, er at broren min ble helt spinnvill av alle lekene som var på flyplassen i Frankfurt. 13-åringen måtte hale en skrikende lillebror ut av lekerommet. Abdul, som aldri tidligere hadde vært i et fly, klarte ved hjelp av kroppsspråk og noen få engelske ord å finne riktig utgang for flyet som skulle bringe dem helt fram. Plastikklomme med «reiser alene» rundt halsen var det ingen som hadde tenkt på.

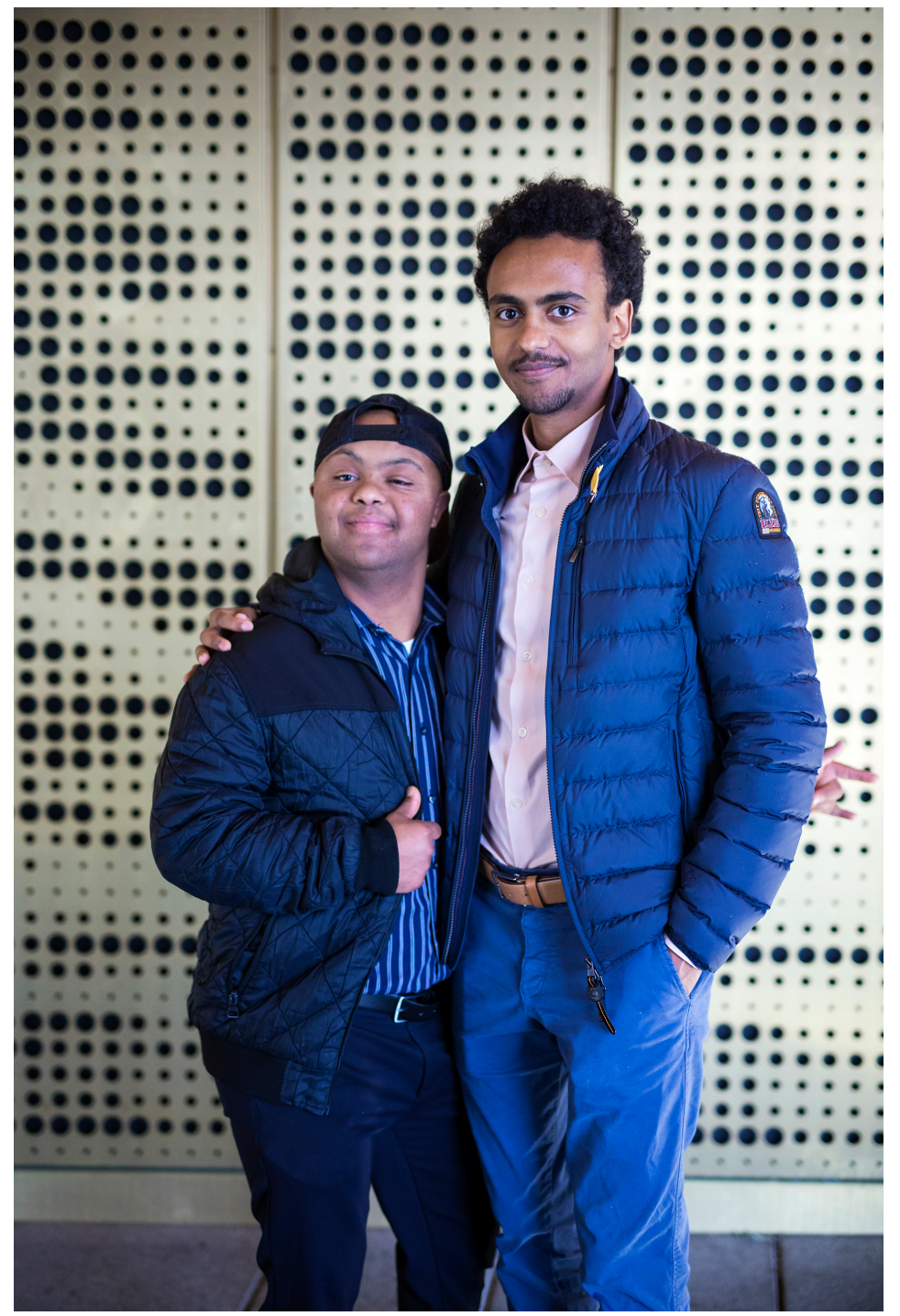

Båndene mellom de to brødrene ble enda sterkere da guttene fikk beskjed om at moren var død kun 
- Smilet til broren min var gull verdt på den turen. Folk blir velvillige av store smil, sier Abdul, som husker følelsen av å være både oppspilt, ansvarsbevisst og urolig på samme tid.

- Jeg hadde sett New Yorks skyline på TV og trodde at det var dit jeg skulle. Det var jo som et eventyr, men samtidig var det noe som ikke stemte. Alle hadde vært så triste da vi dro. Ikke minst var mor så trist.

Fortsatt blir jeg trist av å vite at celleprøvescreening og en enkel konisering mest sannsynlig ville ha gitt mor et langt liv

Moren ville ikke, eller maktet aldri, å fortelle at hun var dødssyk. Bare noen uker etter at guttene var installert i en køyeseng på et barnerom hos søsteren og hennes to barn i en liten leilighet på Ammerud, fikk Abdul beskjed om morens død. Etiopiere fra Oslo og Bergen som Abdul så vidt hadde sett før, kom på døren med mat og trøst. Noen lå over til dagen etter.

- Selv om jeg ikke kjente dem så godt, husker jeg at det var veldig fint at de kom. Det gjorde det lettere. Men ... fortsatt blir jeg trist av å vite at celleprøvescreening og en enkel konisering mest sannsynlig ville ha gitt mor et langt liv.

\section{Vanskelig å fortelle historien}

Det ringer på dørklokken. Søsteren til Abdul kommer innom. Det er fristende å spørre om hennes opplevelse av tiden da guttene kom.

- Tenk, vi har aldri snakket om det, sier hun og skotter bort på Abdul. Så forteller hun om hvor viktig Abdul var for å kunne håndtere Mabruks mange nykker.

- Abdul var helt enestående, sier søsteren, som i samme sekund oppdager at hennes sønn nå er like gammel som det Abdul var da han kom til Norge.

- Sønnen min kan jo ikke engang klare å huske tre ting når jeg sender han på butikken, avslutter hun med tårer i øynene.

Abdul innrømmer at det er tungt å fortelle fra barndommen. Han signaliserer at det får være nok for i kveld.

- Det med mor er jo så trist. Det er ikke så ofte jeg snakker om barndommen, sier han. Men likevel vil han ikke slutte historiefortellingen. Han vil finne en ny dato for å fortsette intervjuet.

- Og hva med å ta bilder sammen med broren din?

- Ja, gjerne!

\section{Visum}

Det tar et par måneder og en koronatid før det er mulig med et nytt møte. Ekteparet kommer gående med Mabruk mellom seg. Han er først sjenert, men tør opp etter å ha gjemt seg inni dunjakken til bror og svigerinne utallige ganger. Kamera legges bort, og historien fra 13 år tilbake i tid fortsetter. 


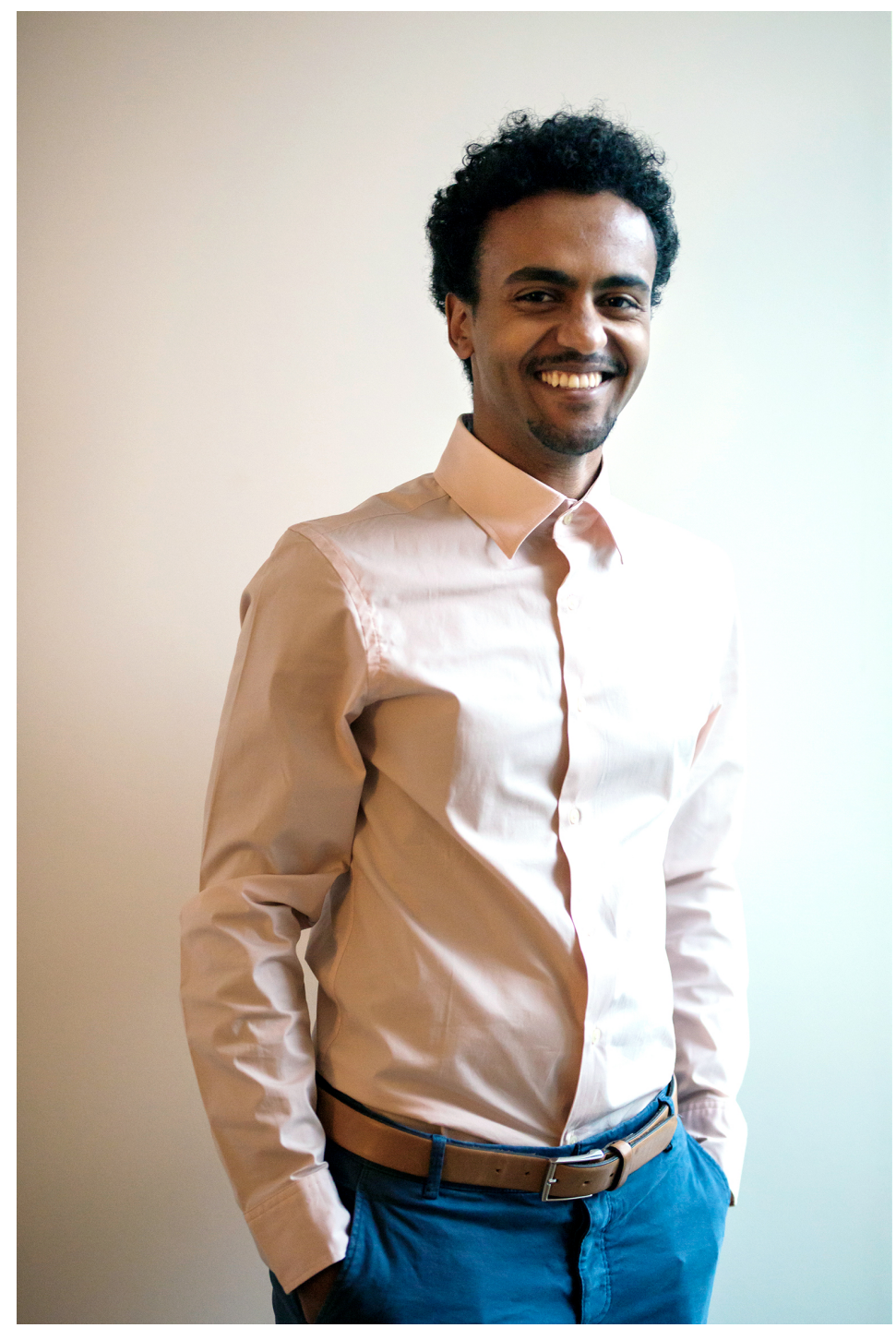

Abdul ønsker Tidsskriftet velkommen inn i ekteparets leilighet. Foto: Kristine Lindebø

Etter at den akutte sorgen over morens død la seg, sto nye problemer i kø. Med kun turistvisum hadde brødrene ingen rettigheter i Norge. Søsteren jobbet sammen med advokater i månedsvis for å overbevise den norske stat om at naboene i hjembyen ikke kunne ta over foreldreansvaret. Imens oppholdt guttene seg alene hjemme på formiddagene, mens søsteren var på jobb. Abdul husker det som en kort periode, men søsteren fortalte sist at det gikk nesten et helt år før oppholdstillatelsen var i boks. Først da fikk Abdul endelig starte i en innføringsklasse. Der lærte han seg norsk på et halvår, før han ble plassert i g. klasse på Ammerud ungdomsskole. Der ble han ifølge Sara «den kuleste gutten i klassen». Det har guttene i Abduls ungdomsskoleklasse fortalt henne.

- Jeg ble i alle fall godt mottatt, smiler Abdul beskjedent.

\section{Videregående skole}

Året etter sklir Abdul rett inn på Nydalen videregående skole, en høyt rangert skole. Livshistorien sitter i tenåringskroppen fra Etiopia. Brorens positive utvikling etter at han fikk diagnosen Downs syndrom og det ble satt i gang tiltak, har gjort inntrykk. Tanken på at moren kunne ha fått leve videre, slipper heller ikke taket. Avgjørelsen om yrkesvalg er allerede tatt. Målet er å bli lege.

- Jeg gikk glipp av mye i ungdomstida. Det ble mye pugging. Lærerne på skolen og leksehjelpen som Røde Kors hadde på Grønland og på Grorud, var helt uvurderlig.

Til tross for hard jobbing på videregående skole, tar Abdul seg innimellom tid til å kikke på jentene. Den store kjærligheten blomstrer da han oppdager Sara i klassetrinnet under. 
- Jeg fant verdens beste dame, smiler Abdul, som er ærlig på at det føltes stadig trangere i leiligheten hos søsteren som på det tidspunktet hadde fått fire egne barn. Abdul flytter inn til Saras familie - på soverommet til Saras bror. Sara har norsk mor og iransk far.

- Var det viktig for deg at Sara har det vi vel må kalle multikulturell bakgrunn?

- Overhodet ikke. Jeg trodde hun var helnorsk, jeg.

- Har svigerfamilien blitt viktig for deg?

- Selvfølgelig.

Abdul forteller om episoder fra bursdager, feiringer og ikke minst om turen da Abdul, Mabruk og søsteren reiste tilbake til Etiopia sammen med Sara og svigerforeldrene.

De unge ser på hverandre og smiler.

\section{Medisinstudiet}

Karakterkortet fra videregående skole og permanent oppholdstillatelse kommer omtrent samtidig i posten. Med studieplass på medisinsk fakultet i Oslo er veien staket ut.

-Så fikk jeg passet! Den røde boka ble noe spesielt. Den betydde trygghet.

Tryggheten vokste ytterligere etter bryllupet i februar 2015. Da var bruden 20 år og brudgommen 21 år. Sara var i gang med medisinstudiet i Bergen. De pendlet fram og tilbake samtidig som begge var ivrige etter å få seg praksis. Abdul gjorde maksimalt ut av sjetteårsoppgaven og fikk publisert en artikkel om koronare bypassoperasjoner. Med midlertidig lisens ble det mye jobbing både på Kommunal akutt døgnenhet i Oslo, på Diakonhjemmet og ved flere allmennlegekontorer både i Oslo og i Bergen.

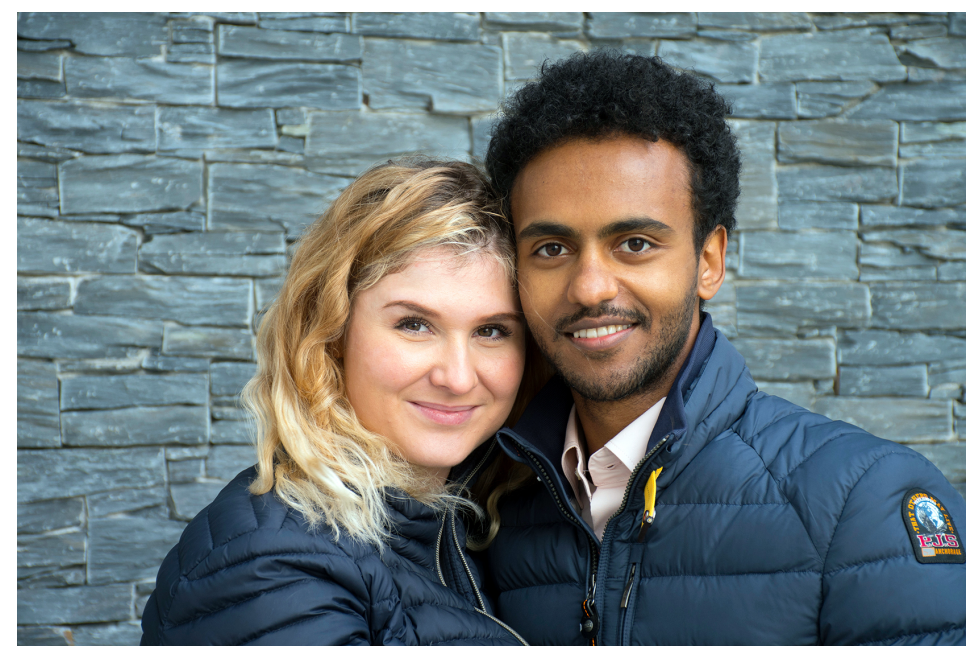

Ekteparet Sara og Abdul Nuru kan etter seks år med pendling mellom Bergen og Oslo endelig bo sammen i Oslo. Foto: Tori Flaatten Halvorsen

Etter ferdig LIS-1-tjeneste på Diakonhjemmet gjenstår bare siste etappe før han kan begynne på spesialisering. Den gjennomfører han for tiden på legekontoret på Haugerud i Oslo. Så lurer han på doktorgrad, men er usikker på hvilket fagfelt som er mest spennende.

- Abdul er ikke så god på ferie, erter Sara.

- Det er jo bare så gøy å se hvordan medisinen fungerer ute i praksis! Og så er det så fint å kunne hjelpe dem som trenger det, understreker han på en troverdig måte.

- Liker du å ha pasienter som kan ha liknende livserfaringer som deg?

- Ikke spesielt, tror jeg. Hvor folk er fra, er vel helt underordnet. Alle har krav på samme hjelp.

Så forteller han en historie fra siste nattevakt der han fikk ekstra god kontakt med en 
pasient fra Eritrea. Begge kunne såpass mye av den varianten av arabisk som snakkes i de to landene, at de klarte å kommunisere bedre enn det pasienten hadde erfart med de legene hun tidligere hadde møtt.

- Det var jammen en god opplevelse, smiler han.

Så stopper Abdul opp. Han ser ut i luften og legger til:

- Det er egentlig fint å få kunne fortelle historien min.

Publisert: 5. november 2020. Tidsskr Nor Legeforen. DOI: 10.4045/tidsskr.20.0846

(C) Tidsskrift for Den norske legeforening 2020. Lastet ned fra tidsskriftet.no 